\title{
GEOQUÍMICA DOS GRANITOS PALEOPROTEROZÓICOS DA SUÍTE GRANITICA VELHO GUILHERME, PROVÍNCIA ESTANÍFERA DO SUL DO PARÁ
}

\author{
NILSON PINTO TEIXEIRA*, JORGE SILVA BETTENCOURT ${ }^{1}$, ROBERTO DALL'AGNOL ${ }^{2}$, \\ CÂNDIDO AUGUSTO VELOSO MOURA ${ }^{2}$, CARLOS MARCELLO DIAS FERNANDES ${ }^{2} \&$ \\ SABRINA CRISTINA CORDOVIL PINHO²
}

\begin{abstract}
GEOCHEMISTRY OF PALEOPROTEROZOIC GRANITES OF THE VELHO GUILHERME GRANITE SUITE, TIN PROVINCE OF SOUTHERN PARÁ, BRAZIL The granitic rocks of the Antônio Vicente, Velho Guilherme, Mocambo, Benedita e Ubim/Sul massifs of the Velho Guilherme Intrusive Suite (South Pará Tin-Province) are hololeucocratic to leucocratic, syenogranite to monzogranite with subordinate alkali-feldspar granite. Geochemical data of representative rock samples from the different massifs of the suite indicated a subalkaline nature, metaluminous to peraluminous character, as well as geochemical affinity whit within-plate and A-type granites of the $\mathrm{A}_{2}$ subgroup. Fractional crystallization was the main petrogenetic process governing the evolution of the granites of the suite. The tin mineralized members are extremely evolved, silica-rich rocks $\left(\mathrm{SiO}_{2}>75 \%\right)$ which are the product of magmatic fractionation and interaction with F-enriched fluids. These fluids were responsible for $\mathrm{Sn}^{2+}$ extraction from primary mineral phases, specially biotite. $\mathrm{Sn}^{2+}$ was then incorporated into the fluids and later oxidized to $\mathrm{Sn}^{4+}$ and precipitaded as cassiterite.

$\mathrm{The} \mathrm{Th} / \mathrm{Ta}$ ratios of the Velho Guilherme (5.06 to 10.46) and Benedita (6.77 to 15.40) granites suggest a dominant contribution of continental upper crustal sources. For the Ubim/Sul granite magma Th/Ta ratios (3.52 to 5.33) indicated comparatively deeper crustal sources. The ultimate source material for the Mocambo granite magma ( $\mathrm{Th} / \mathrm{Ta}$ of 3.03 to 8.26 ) is more probably a mixture of lower and upper continental crust. The variable $\mathrm{Th} / \mathrm{Ta}$ (5 to 100) observed in the Antônio Vicente granite is probably the result of a mixture of continental lower crustal sources with subordinate contribution of sedimentary rocks.
\end{abstract}

Keywords: geochemistry, tin-granite, A-type, Paleoproterozoic, Amazonian craton

Resumo As rochas graníticas dos maciços Antônio Vicente, Velho Guilherme, Mocambo, Benedita e Ubim/Sul, da Suíte Intrusiva Velho Guilherme (Província Estanífera do Sul do Pará) são hololeucocráticas a leucocráticas, sieno a monzograníticas, com tipos álcalifeldspato graníticos subordinados. Dados geoquímicos de rocha total dos diferentes maciços da suíte revelaram a sua natureza subalcalina, caráter metaluminoso a peraluminoso, bem como afinidade tectonomagmática intraplaca e características geoquímicas de granitos tipo-A, do subgrupo $\mathrm{A}_{2}$. A cristalização fracionada foi o principal processo petrogenético que governou a evolução dos granitos da suíte. Os diferenciados mais evoluídos e hospedeiros de mineralizações de Sn mostram um grau extremo de diferenciação $\left(\mathrm{SiO}_{2}>75 \%\right)$ e são produto de fracionamento magmático e da interação com fluidos aquosos pós-magmáticos ricos em voláteis $(\mathrm{F})$. Esses fluidos foram responsáveis pela extração de $\mathrm{Sn}^{2+}$, a partir das fases minerais primárias, especialmente, da biotita, incorporando$o$ às soluções residuais onde foi oxidado, passando para a forma $\mathrm{Sn}^{4+}$ e precipitando como cassiterita. As razões $\mathrm{Th} / \mathrm{Ta}$ dos granitos dos maciços Velho Guilherme $(5,06$ a 10,46) e Benedita $(6,77$ a 15,40) apontam para uma fonte dominantemente de crosta continental superior. Em relação aos granitos do maciço Ubim/Sul, a sua razão $\mathrm{Th} / \mathrm{Ta}(3,52$ a 5,33) sugere uma fonte magmática localizada em um segmento crustal um pouco mais profundo. Já os protólitos dos granitos do maciço Mocambo (razão Th/Ta de 3,03 a 8,26) resultaram mais provavelmente de uma mistura de material de crosta profunda e crosta continental superior. A ampla variação das razões Th/Ta observada nos granitos do maciço Antônio Vicente (5 a 100) sugere uma mistura de componentes de crosta continental superior com uma possível contribuição de natureza sedimentar.

Palavras-chave: geoquímica, granitos estaníferos, Tipo-A, Paleoproterozóico, Cráton Amazônico

INTRODUÇÃO Rochas graníticas paleoproterozóicas do Cráton Amazônico têm sido objeto de diversas investigações (Dall'Agnol et al. 1986, Bettencourt \& Dall'Agnol 1987, Dall'Agnol et al. 1993, Magalhães et al. 1994, Dall'Agnol et al. 1999a, Bettencourt et al. 1999, Costi et al. 2000, Teixeira et al. 2002a). Dentre elas, ocorre um grande número de corpos com características subalcalinas e alcalinas, semelhantes a granitos do tipo "A” (Loiselle \& Wones 1979, Collins et al. 1982), os quais são portadores de mineralizações de estanho e outros metais raros (Bettencourt \& Dall'Agnol 1987, Dall'Agnol et al. 1993, Costi 2001, Teixeira et al. 2002a).

$\mathrm{Na}$ Província Mineral de Carajás, sul-sudeste do Estado do
Pará, ocorrem diversos maciços graníticos com greisens associados, alguns portadores de mineralizações de estanho. Tais maciços estão reunidos sob a designação de Suíte Intrusiva Velho Guilherme (CPRM/DNPM 1997, Teixeira et al. 2002a), cujos corpos graníticos fazem parte da Província Estanífera do Sul do Pará (Abreu \& Ramos 1974). Nas duas últimas décadas esses granitos foram tema de inúmeras investigações, com diferentes enfoques (Teixeira \& Dall'Agnol 1991, Teixeira \& Andrade 1992, Dall'Agnol et al. 1993b, Magalhães et al. 1994, Lafon et al. 1995, Teixeira et al. 2002a). Entretanto, estudos voltados para a caracterização geoquímica das rochas da suíte, bem como investigações que

\footnotetext{
* - In memoriam

1 - Instituto de Geociências da Universidade de São Paulo, Caixa Postal 11348, CEP 05422-970, São Paulo, São Paulo, Brasil. FAX: 55-11-818-4207 jsbetten@usp.br.

2 - Centro de Geociências da Universidade Federal do Pará, Caixa Postal 1611. CEP 66075-900. Belém, Pará, Brasil. FAX : 55-91- 211-1609. E-mails: robdal@ufpa.br, c_moura@ufpa.br,cmdf@ufpa.br, sabrinapinho@bol.com.br
} 
visam discutir o potencial metalogenético das mesmas são escassos e/ou pouco aprofundados.

Objetivando preencher essas lacunas, foram realizadas análises químicas em rocha total para elementos maiores, traço e ETR em rochas dos maciços Antônio Vicente, Velho Guilherme, Mocambo, Benedita e Ubim/Sul, para caracterizá-los geoquímicamente e discutir seu potencial metalogenético e os processos formadores das mineralizações de cassiterita associadas.

CONTEXTO REGIONAL Os principais depósitos da Província Estanífera do Sul do Pará se associam com as rochas graníticas da Suíte Intrusiva Velho Guilherme, situada no contexto do Cráton Amazônico (Almeida et al. 1981), no domínio geocronológico da Província Amazônia Central (> 2.3 Ga, Tassinari \& Macambira 1999).

A área de ocorrência dos maciços da Suíte Intrusiva Velho Guilherme foi palco de diversos eventos termo-tectônicos do Arqueano e do Proterozóico, testemunhados por transformações mineralógicas e elementos estruturais impressos em unidades litoestratigráficas arqueanas do Terreno Granito-Greenstone do Sul do Pará e do Cinturão de Cisalhamento Itacaiúnas (Araújo et al. 1988). Nesta área ocorrem, ainda, o Granito Parauari e vulcânicas intermediárias (Formação Sobreiro) e félsicas (Formação Iriri) paleoproterozóicas (CPRM/DNPM 1997).

Os corpos graníticos são intrusivos em seqüências metavulcanossedimentares do Grupo Tucumã (Araújo et al. 1988), no Granodiorito Rio Maria (Medeiros et al. 1987), ambos pertencentes ao Terreno Granito-Greenstone do Sul do Pará (Araújo et al. 1988), e no Cinturão de Cisalhamento Itacaiúnas (Araújo et al.
1988), todos arqueanos, e no Granito Parauari (Lafon et al. 1991) e rochas vulcânicas do Grupo Uatumã, do Paleoproterozóico (Fig. 1).

\section{ASPECTOS GEOLÓGICOS DOS MACIÇOS ESTUDADOS}

Os granitos da Suíte Intrusiva Velho Guilherme são mineralizados em estanho, sendo os depósitos explotados de natureza aluvionar. As fácies graníticas afetadas por alteração hidrotermal pósmagmática e os greisens hospedam pequenas concentrações primárias de cassiterita (Teixeira \& Bettencourt 2000).

$\mathrm{O}$ caráter francamente discordante dos corpos em relação às encaixantes, a presença de rochas vulcânicas não metamorfísadas e de seqüências supracrustais entre as mesmas, o desenvolvimento de auréolas de contato de baixa pressão (Dall'Agnol 1980) e a freqüencia de intercrescimentos granofíricos em algumas fácies dos maciços, bem como a ocorrência de granitos pórfiros, sugerem que a colocação destes foi rasa, por vezes subvulcânica (Teixeira \& Dall'Agnol 1991, Teixeira 1999). Nestas condições, a relação cristais-líquido não deveria ser elevada quando da colocação dos mesmos (Pitcher 1979). Tais aspectos ocorrem em outros granitos anorogênicos ou pós-tectônicos da Amazônia (Dall'Agnol 1980, Gastal 1987, Gonçalez et al. 1988, Daoud 1988, Dall'Agnol et al. 1994, 1999a; Lamarão et al. 2002).

Estudos petrográficos mostram que os granitos dos diferentes maciços são hololeucocráticos a leucocráticos, sieno a monzograníticos, subordinadamente álcali-feldspato graníticos (Fig. 2).

O maciço Antônio Vicente foi estudado mais detalhadamente por Dall'Agnol (1980), Teixeira \& Dall'Agnol (1991), Dall'Agnol et

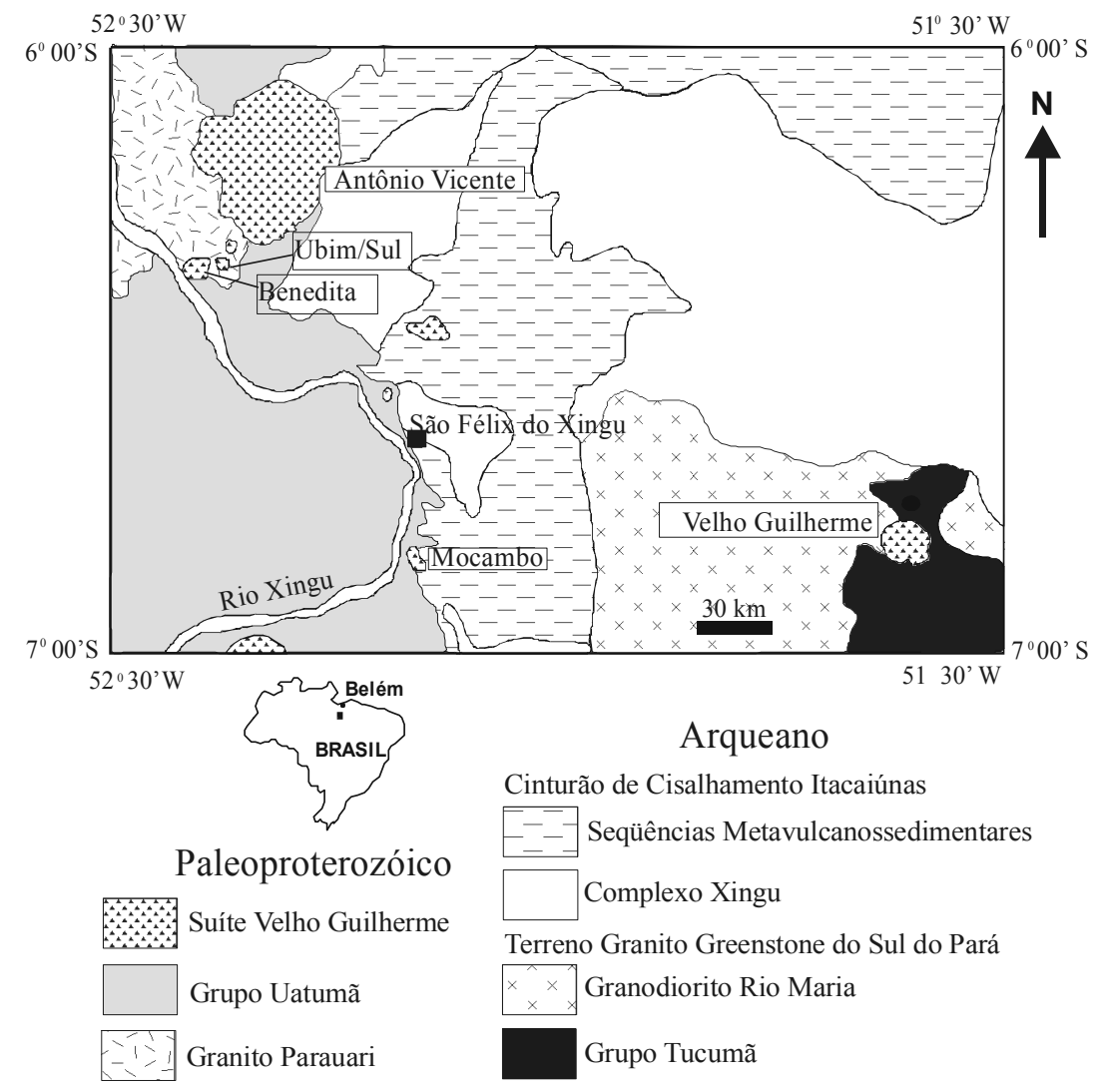

Figura 1 - Mapa geológico simplificado da Folha SB-22-Y-B (Folha São Félix do Xingu), mostrando a distribuição dos maciços graniticos da Suite Intrusiva Velho Guilherme estudados (CPRM/DNPM 1997, modificado). 
al. (1993b), Magalhães et al. (1994), Teixeira et al. (2002a,b). Datações ${ }^{207} \mathrm{~Pb} /{ }^{206} \mathrm{~Pb}$ em zircão por evaporação de $\mathrm{Pb}$ indicaram uma idade de $1867 \pm 4$ Ma para o maciço (Teixeira et al. 2002a). Teixeira \& Dall'Agnol (1991) distinguiram no interior do maciço quatro domínios petrográficos principais (Fig. 2): 1-biotita-anfibóliosienogranito com biotita-anfibólio-monzogranito subordinado, pouco afetados por alterações pós-magmáticas; 2-anfibólio-biotitasienogranito, biotita-anfibólio-sienogranito a álcali-feldspato-granito, biotita-sienogranito com clorita e álcali-feldspato-granito; 3biotita-sienogranito com biotita-monzogranito subordinado. Aúltima variedade está afetada, em diferentes graus, por alterações pós-magmáticas, por vezes muito intensas; 4-biotita-monzogranito, sem alterações importantes, com biotita-sienogranito subordinado. Localmente, foram caracterizados micromonzogranito e sienogranito a monzogranito granofírico.

Associados ao biotita-sienogranito (3), ocorrem zonas e corpos de greisens e veios de fluorita de espessura milimétrica e centimétrica. Dentre os greisens foram distinguidos: a) muscovitaquartzo-greisen; b) clorita-quartzo-greisen; c) clorita-siderofilitamuscovita-quartzo-greisen.

Apesar das variações composicionais, os granitos guardam entre si muitas semelhanças texturais. A maioria têm textura hipidiomórfica equigranular grossa ou média, por vezes porfirítica, e, com mais freqüência, textura seriada grossa a média ou média a fina. São geralmente acinzentados, localmente rosados. Tons avermelhados e acinzentados ocorrem em corpos mais intensamente afetados por alterações pós-magmáticas.

Quartzo, álcali-feldspato pertítico e plagioclásio sódico (albitaoligoclásio) são os minerais essenciais. As bandas sódicas das pertitas, originadas por processos de exsolução (em cordões ou filmes) e de espessamento (em bandas, veios e manchas), por vezes, associadas com substituição (conforme Smith \& Brown 1988), são abundantes. Intercrescimentos granofíricos estão comumente presentes.

A siderofilita é o máfico principal das fácies mais evoluídas desprovidas de anfibólio (Teixeira et al. 2002a). Anfibólio com composição de alumínio-hastingsita a alumínio-ferro-edenita, as-

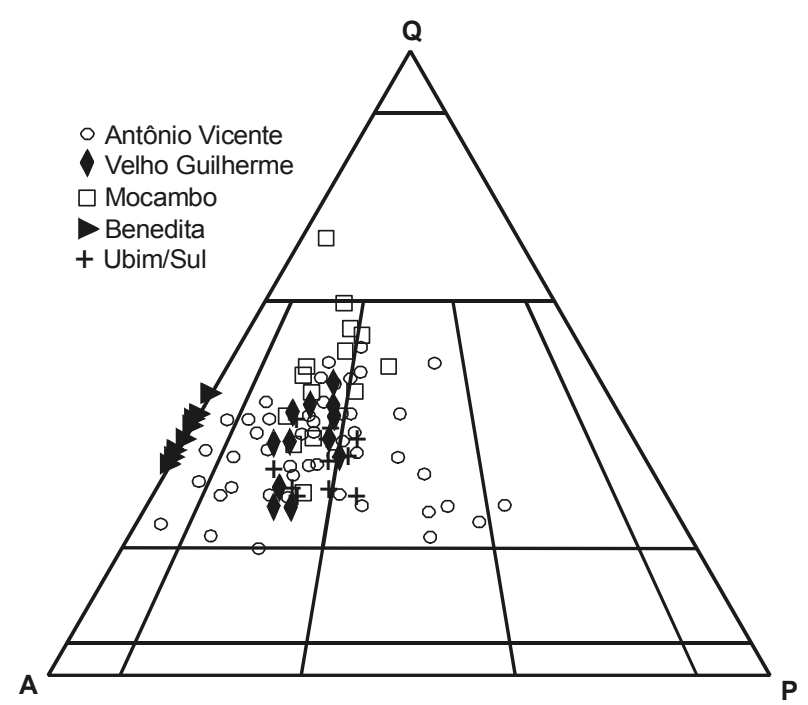

Figura 2-Diagrama Q-A-P mostrando a distribuição composicional modal dos granitos estudados (Teixeira 1999, modificado). Campos conforme Streckeisen (1976). sociado com biotita comparativamente mais magnesiana, ocorre nos granitos relativamente menos evoluídos (biotita-anfibóliosieno a monzogranito). Os acessórios incluem zircão, ilmenita, magnetita, titanita e apatita. Os minerais de alteração pós-magmática são sericita, fengita (Fernandes 2003), clorita, fluorita, epidoto, topázio, microclina, albita, allanita e minerais de argila. Cassiterita, calcopirita, estanita, fluocerita-(Ce), esfalerita, itrocerita, monazita e xenotímio estão associados aos granitos mais alterados e aos mica-quartzo-greisens.

O maciço Velho Guilherme foi investigado por Dall'Agnol (1980) e, em maior detalhe, por Teixeira (1999). Datações radiométricas $\mathrm{Pb}-\mathrm{Pb}$ em rocha total revelaram uma idade de $1874 \pm$ $30 \mathrm{Ma}$ (Lafon et al. 1995). Neste maciço, Teixeira (1999) caracterizou três variedades principais: a) biotita-sienogranito equigranular médio; b) sienogranito heterogranular; c) microssienogranito (Fig. 2). Evidências de campo indicam que o biotita sienogranito equigranular é seccionado pelo sienogranito heterogranular e que esse último é cortado pelo microssienogranito e veios hidrotermais com epidoto e quartzo. Os tipos graníticos estão afetados, em diferentes intensidades, por alterações pós-magmáticas. São sienograníticos subsolvus, hololeucocráticos e se originaram a partir de líquidos muito diferenciados e evoluídos, extremamente silicosos. Guardam muita semelhança com a fácies biotitasienogranito do maciço Antônio Vicente.

Quartzo, plagioclásio $\left(\mathrm{An}_{12-6}\right)$ e feldspato potássico (microclina pertítica) são fases essenciais, sendo a biotita, de composição anítica aluminosa, o principal constituinte máfico. Zircão, ilmenita e magnetita são fases acessórias primárias, enquanto sericita, muscovita, clorita, fluorita, topázio, microclina, albita, esfalerita, allanita, epidoto, carbonato, fluocerita, cério-pirocloro, fergusonita e minerais argilosos são de alteração pós-magmática.

O maciço Mocambo é uma cúpula intensamente afetada por alterações pós-magmáticas. Os granitos expostos resultam da interação do granito original com fluidos residuais ricos em voláteis (F). Datações geocronológicas por evaporação de $\mathrm{Pb}$ em zircão, indicaram uma idade de $1862 \pm 32$ Ma para o maciço Mocambo (Teixeira et al. 2002a). Estudos petrográficos (Teixeira 1999) revelaram três fácies: 1) sienogranito a monzogranito porfirítico; 2) sienogranito com muscovita; 3 ) álcali-feldspato-granito aplítico (Fig. 2). Ocorre, ainda, um corpo de siderofilita-clorita-muscovitaquartzo-greisen, interpretado como produto de alterações pósmagmáticas mais intensas sobre o sienogranito com muscovita. As relações de contato entre as diversas fácies não foram observadas diretamente durante os trabalhos de campo.

Apesar de marcantes diferenças texturais, os granitos consistem de quartzo, feldspato potássico e plagioclásio, acompanhados por mica com composição de annita aluminosa a siderofilita, presente nas variedades sieno a monzogranito porfirítico e sienogranito com muscovita (Teixeira 1999). Como minerais acessórios ocorrem zircão, ilmenita e magnetita.

Sericita-muscovita, clorita, fluorita, epidoto, topázio, carbonato e microclina reultaram da substituição parcial do plagioclásio ou da desestabilização da biotita e albita e minerais de argila à alteração do feldspato potássico. A cristalização da cassiterita foi tardia e ocorreu durante a oxidação das micas primárias (Teixeira 1999). Ocorrem ainda allanita, monazita, fluocerita, esfalerita, pseudo-ixiolita/ferro-columbita, volframo-ixiolita, itrofluorita e itrocerita.

O siderofilita-clorita-muscovita-quartzo-greisen foi observado em apenas um afloramento, na zona de contato da fácies sienogranito com muscovita e suas encaixantes. Apresenta as- 
pecto maciço, textura hipidiomórfica, heterogranular, granulação fina a média e coloração cinza escura a negra. Consiste essencialmente de quartzo, muscovita, clorita e siderofilita. Como fases minerais residuais primárias ocorrem zircão, hematita e magnetita, sendo fases tardias, subordinadas, albita, fluorita e cassiterita.

O maciço Benedita (Teixeira \& Andrade 1992) é intrusivo no Granito Parauari e em rochas vulcânicas félsicas da Formação Iriri do Grupo Uatumã (Fig. 1). É formado por um (biotita)-álcalifeldspato-granito hololeucocrático (Fig. 2) hipersolvus (Tuttle \& Bowen 1958), avermelhado a rosa esbranquiçado e textura hipidiomórfica, heterogranular, fina a média. Textura granofírica ocorre localmente. Os minerais essenciais compreendem quartzo e feldspato potássico, e os acessórios são biotita, zircão e minerais opacos. Minerais de alteração pós-magmática são pouco expressivos e representados por sericita, muscovita, albita, fluorita, clorita, pirita, óxido de Fe e W e minerais de argila.

O maciço Ubim/Sul é intrusivo no Granito Parauari e faz contato com rochas vulcânicas félsicas da Formação Iriri do Grupo Uatumã. Mostra caráter hololeucocrático e ocupa os campos do sienogranito e monzogranito (Fig. 2). Teixeira \& Andrade (1992) caracterizam duas fácies no maciço: (1) biotita-sienogranito com clorita e (2) biotita-monzogranito. Ambas variedades têm textura hipidiomórfica, heterogranular, granulação média a grossa e coloração rosa a rosa-esbranquiçada. Consistem essencialmente de quartzo, feldspato potássico e plagioclásio, sendo varietal a biotita. As fases minerais acessórias primárias são zircão e minerais opacos (de composição não determinada), enquanto aquelas tardias, associadas às alterações pós-magmáticas, são sericita-muscovita, microclina, albita, esfalerita, minerais opacos, quartzo, minerais de argila, topázio, monazita e cassiterita \pm clorita \pm fluorita.

GEOQUÍMICA As análises químicas de elementos maiores, menores e traços, exceto $\mathrm{FeO}$, Li e ETR (apenas para o maciço Antônio Vicente), dos granitos estudados foram realizadas no ACTLABS (Activation Laboratories Ltd, Canadá), com abertura por fusão. As análises dos elementos maiores foram realizadas por ICP-ES (Inductively Coupled Plasma-Emission Spectrometry), e dos elementos traços (exceto $\mathrm{F}$ e $\mathrm{Cl}$ ) por ICP-MS (Inductively Coupled Plasma-Mass Spectrometry). O F foi analisado pelo método SIE (Selective Ion Electrode) e o Cl pelo método INAA (Instrumental Neutron Activation Analysis). As análises de FeO, Li e ETR de amostras do maciço Antônio Vicente foram realizadas no Service D'Analyses des Roches et Minéraux do Centre de Recherches Pétrographiques et Géochimiques (CRPG - NancyFrança). Os dois primeiros por via úmida e os ETR por ICP-MS.

As composições químicas médias de 47 amostras de granitos dos maciços estudados, bem como algumas razões específicas entre óxidos maiores, elementos traço e terras raras são mostradas na Tabela 1.

Os dados litogeoquímicos mostraram que as rochas graníticas da Suíte Intrusiva Velho Guilherme possuem natureza subalcalina (Fig. 3), caráter metaluminoso a peraluminoso (Fig. 4), afinidade geoquímica com granitos intra-placa (Fig. 5) e uma grande semelhança com granitos tipo-A, do subgrupo $\mathrm{A}_{2}$, exceto em relação ao maciço Benedita, que incide no campo dos granitos do subgrupo $\mathrm{A}_{1}$ (Fig. 6). Exibem conteúdos sempre baixos de $\mathrm{TiO}_{2}, \mathrm{Al}_{2} \mathrm{O}_{3}, \mathrm{CaO}$, $\mathrm{MgO}$ e $\mathrm{P}_{2} \mathrm{O}_{5}$, inferiores àqueles da média dos granitos reportada por Le Maitre (1976). Possuem conteúdos aproximadamente iguais de $\mathrm{Na}_{2} \mathrm{O}$ e $\mathrm{K}_{2} \mathrm{O}$ e o total de álcalis $\left(\mathrm{Na}_{2} \mathrm{O}+\mathrm{K}_{2} \mathrm{O}\right)$ varia de 7,12 a 8,91 (\% em peso), refletindo o caráter subalcalino dos granitos estudados. As razões $\mathrm{K}_{2} \mathrm{O} / \mathrm{Na}_{2} \mathrm{O}$ são sempre superiores a 1 (Tabela 1) e se situam entre 1,01 (fácies álcali-feldspato-granito do maciço Benedita) e 3,14 (fácies aplito do maciço Mocambo).

Possuem, em geral, conteúdos baixos de $\mathrm{Sr}$, $\mathrm{Ba}$ e $\mathrm{Cl}$, moderados de Hf, U e Zr, e sistematicamente altos de Rb, Y, F, Li, Th, Nb, Ta e Ga, exceto nos granitos do maciço Antônio Vicente onde os teores de Ga são invariavelmente mais baixos (Tabela 1), relativamente aos conteúdos dos granitos dos demais maciços. Como conseqüência, as razões $\mathrm{Rb} / \mathrm{Sr}, \mathrm{Rb} / \mathrm{Ba}$, e $\mathrm{F} / \mathrm{Cl}$ são, via de regra, altas, especialmente nas variedades portadoras de mineralizações de $\mathrm{Sn}$. As razões $\mathrm{K} / \mathrm{Rb}$ são muito baixas, se comparadas com aquelas dos granitos considerados não especializados (Shaw 1968). No diagrama Rb-Ba-Sr (Fig. 7), nota-se que as composições das diferentes fácies graníticas incidem, com raras exceções, no campo dos granitos extremamente diferenciados.

Elementos Terras Raras (ETR) das rochas graníticas do maciço Antônio Vicente exibem teores médios mais elevados, especialmente nas fácies pouco efetadas por processos hidrotermais pósmagmáticos, cujos conteúdos situam-se entre 872,93 e 420,72 ppm (Tabela 1). As mais baixas concentrações médias desses elementos encontram-se nos granitos dos maciços Velho Guilherme e Benedita e variam entre 186,56 ppm e 155,03 ppm. Os granitos dos maciços Mocambo e Ubim/Sul possuem valores médios oscilando entre 241,75 e 354,69 ppm (Tabela 1), os quais são equivalentes àqueles encontrados nas fácies mais intensamente afetadas por alterações hidrotermais pós-magmáticas do maciço Antônio Vicente (Tabela 1). Todos os granitos dos maciços estudados mostram um padrão de distribuição dos ETR do tipo gaivota e possuem uma forte anomalia negativa $\mathrm{de} \mathrm{Eu}\left(\mathrm{Eu} / \mathrm{Eu}^{*}=0,33 \mathrm{a} 0,006\right)$, embora nos maciços Velho Guilherme, Mocambo, Benedita e Ubim/ Sul esta seja mais acentuada $\left(\mathrm{Eu} / \mathrm{Eu}^{*}=0,032\right.$ a 0,006$)$, relativamente ao maciço Antônio Vicente $\left(\mathrm{Eu} / \mathrm{Eu}^{*}=0,33\right.$ a 0,06; Fig. 8). A razão $(\mathrm{La} / \mathrm{Lu})_{\mathrm{N}}$ é mais elevada nos granitos do maciço Antônio Vicente, especialmente nas fácies pouco afetadas por alterações hidrotermais pós-magmáticas, onde a mesma alcança valores entre 25,96 e 9,96 (Tabela 1), indicando um fracionamento moderado dos ETRP em relação aos ETRL. Nos granitos dos demais maciços, os baixos valores desta razão $(2,85$ a 0,99$)$ evidenciam um fracionamento fraco e/ou ausente dos ETRP em comparação aos ETRL. Isso indica a tendência ao decréscimo gradual dos ETRL para as fácies mais evoluídas e ricas em sílica, paralelamente ao aumento relativo dos conteúdos de ETRP, resultando nos padrões em gaivota típicos dessas rochas. Entre os ETRL, nota-se um fracionamento interno moderado, expresso pelas razões $(\mathrm{La} /$ $\mathrm{Sm})_{\mathrm{N}}$, cujos valores variam de 6,19 a 1,67, nos granitos do maciço Antônio Vicente, e de 4,75 a 1,20 nos granitos dos demais maciços. Foge a essa característica a fácies micro-sienogranito do maciço Velho Guilherme com valor médio da razão $(\mathrm{La} / \mathrm{Sm})_{\mathrm{N}}$ de 0,4 . Em relação ao fracionamento interno dos ETRP, observam-se valores sistematicamente baixos da razão $(\mathrm{Gd} / \mathrm{Lu})_{\mathrm{N}}$, que varia entre 0,90 e 0,38 na ampla maioria dos granitos, o que indica um enriquecimento dos elementos terras raras mais pesados e se reflete em padrões subhorizontalizados. Esse efeito é geralmente explicado pela influência do flúor, que favorece a concentração de ETRP nos líquidos tardios (Collins et al. 1982, Whalen et al. 1987, Dall'Agnol et al. 1993, Teixeira 1999). As fácies pouco afetadas por alterações hidrotermais pós-magmáticas do maciço Antônio Vicente, cujos valores são superiores a 1 (Tabela 1), constituem uma exceção.

DISCUSSÕES Acristalização fracionada foi o principal processo petrogenético que governou a evolução dos granitos da Suíte Intrusiva Velho Guilherme (Teixeira \& Bettencourt 2000), formada 
predominantemente por granitos evoluídos que mostram um grau extremo de diferenciação $\left(\mathrm{SiO}_{2}>75 \%\right)$ e são hospedeiros de mineralizações de $\mathrm{Sn}$. Tais granitos são produto de fracionamento magmático e da interação com fluidos hidrotermais aquosos pós- magmáticos, conforme evidenciado por sua distribuição nos diagramas $\mathrm{Sn}$ vs $\mathrm{TiO}_{2}$ e $\mathrm{Sn}$ vs $\mathrm{Rb} / \mathrm{Sr}$ (Fig. 9). Esses fluidos ricos em voláteis (F) foram responsáveis pela extração de $\mathrm{Sn}^{2+}$, a partir das fases minerais primárias, especialmente, da biotita, incorporando-

Tabela 1 - Composições químicas e razões médias de rochas graníticas da Suite Intrusiva Velho Guilherme. Óxido em \% em peso e elementos traço e terras raras em ppm.

\begin{tabular}{|c|c|c|c|c|c|c|c|c|c|c|c|c|c|c|c|c|}
\hline \multirow{2}{*}{$\begin{array}{l}\text { Maciços } \\
\text { Fácies }\end{array}$} & \multicolumn{6}{|c|}{ Antônio Vicente } & \multicolumn{3}{|c|}{ Velho Guilherme } & \multicolumn{3}{|c|}{ Mocambo } & \multicolumn{2}{|c|}{ Benedita } & \multicolumn{2}{|c|}{ Ubim/Sul } \\
\hline & BASMG & $\overline{\mathrm{BSGCl}}$ & BMG & BSG & BSGA & BSGIA & BSGEm & SGH & MSG & SMGP & SGMv & AP & AFG & $\overline{B A F G}$ & $\mathrm{BSGCl}$ & BMG \\
\hline № de amostras & 3 & 2 & 3 & 5 & 4 & 6 & 4 & 5 & 1 & 2 & 2 & 1 & 3 & 3 & 4 & 2 \\
\hline $\mathrm{SiO}_{2}$ & 68,38 & 72,90 & 75,41 & 76,34 & 77,12 & 75,06 & 75.90 & 76,42 & 77,41 & 75,91 & 75,95 & 76,76 & 77,77 & 77,52 & 75,92 & 76,21 \\
\hline $\mathrm{TiO}_{2}$ & 0,78 & 0,31 & 0,18 & 0,14 & 0,09 & 0,05 & 0.05 & 0,05 & 0,03 & 0,04 & 0,06 & 0,04 & 0,043 & 0,04 & 0,04 & 0,04 \\
\hline $\mathrm{Fe}_{2} \mathrm{O}_{3}$ & 1,99 & 1,55 & 1,52 & 0,34 & 0,35 & 0,26 & $1.54+$ & $1,14+$ & $0,48+$ & $2,40+$ & $3,05+$ & $1,02+$ & $1,37+$ & $1,58+$ & $2,19+$ & $1,78+$ \\
\hline $\mathrm{FeO}$ & 2,80 & 1,48 & 1,29 & 1,36 & 1,09 & 0,90 & ndt & ndt & ndt & ndt & ndt & ndt & ndt & ndt & ndt & Ndt \\
\hline $\mathrm{MnO}$ & 0,06 & 0,04 & 0,01 & 0,03 & 0,02 & 0,02 & 0.015 & $<0,012$ & nd & 0,06 & 0,09 & 0,02 & $<0,013$ & $<0,01$ & 0,03 & 0,04 \\
\hline $\mathrm{MgO}$ & 0,81 & 0,17 & 0,18 & 0,12 & 0,05 & 0,02 & 0,01 & 0,03 & 0,03 & 0,02 & 0,01 & 0,02 & 0,02 & $<0,01$ & 0,02 & 0,06 \\
\hline $\mathrm{CaO}$ & 1,67 & 0,48 & 0,48 & 0,73 & 0,77 & 1,02 & 0,49 & 1,01 & 0,53 & 0,57 & 0,58 & 0,43 & 0,13 & 0,27 & 0,50 & 0,74 \\
\hline $\mathrm{Na}_{2} \mathrm{O}$ & 3,93 & 2,01 & 3,34 & 3,28 & 3,50 & 3,27 & 3,60 & 3,78 & 3,25 & 3,25 & 2,59 & 2,03 & 3,99 & 4,15 & 2,84 & 2,48 \\
\hline $\mathrm{K}_{2} \mathrm{O}$ & 4,12 & 6,11 & 5,13 & 4,74 & 4,76 & 4,72 & 4,63 & 4,27 & 5,66 & 4,03 & 4,53 & 6,38 & 4,01 & 4,22 & 4,74 & 4,73 \\
\hline $\mathrm{P}_{2} \mathrm{O}_{5}$ & 0,24 & 0,05 & 0,06 & 0,03 & 0,02 & 0,02 & 0,01 & $<0,01$ & 0,03 & 0,01 & 0,01 & 0,01 & $<0,01$ & $<0,013$ & 0,015 & 0,07 \\
\hline P.F. & 0,88 & 1,20 & 0,69 & 0,81 & 0,68 & 0,84 & 0,70 & 0,50 & 0,52 & 0,85 & 1,14 & 0,89 & 0,48 & 0,48 & 0,93 & 1,16 \\
\hline Total & 99,68 & 99,83 & 100,59 & 100,19 & 100,81 & 99,62 & 99,32 & 99,12 & 100,57 & 100,08 & 100,63 & 100,24 & 99,36 & 100,39 & 99,52 & 99,66 \\
\hline $\mathrm{Rb}$ & 248 & 362 & 296 & 306 & 443 & 539 & 511 & 433 & 365 & 835 & 786 & 871 & 351 & 489 & 662 & 698 \\
\hline $\mathrm{Ba}$ & 1170 & 917 & 447 & 245 & 129 & 29 & 16 & 175 & 264 & 310 & 28 & 32 & 45 & 7 & 25 & 37 \\
\hline $\mathrm{Sr}$ & 148 & 62 & 42 & 34 & 25 & 11 & 9 & 70 & 49 & 21 & 18 & 19 & 15 & 11 & 13 & 60 \\
\hline $\mathrm{Zr}$ & 327 & 351 & 201 & 167 & 132 & 118 & 130 & 121 & 161 & 118 & 164 & 152 & 354 & 269 & 119 & 67 \\
\hline $\mathrm{Nb}$ & 17 & 13 & 21 & 25 & 42 & 51 & 38 & 41 & 52 & 126 & 76 & 120 & 62 & 75 & 79 & 71 \\
\hline $\mathrm{Y}$ & 112 & 144 & 25 & 57 & 83 & 148 & 107 & 122 & 237 & 151 & 170 & 79 & 68 & 89 & 121 & 177 \\
\hline $\mathrm{Be}$ & 3 & 2 & 4 & 5 & 5 & 10 & 4 & 6 & 5 & 2 & 3 & 2 & 3 & 3 & 5 & 8 \\
\hline $\mathrm{Zn}$ & 56 & 65 & 28 & 24 & 23 & 25 & 27 & 22 & 87 & 105 & 126 & 247 & 45 & 49 & 35 & 50 \\
\hline $\mathrm{Ga}$ & 6 & 11 & 6 & 3 & 9 & 18 & 30 & 29 & 28 & 32 & 37 & 32 & 26 & 31 & 27 & 28 \\
\hline Mo & 3,86 & 2,84 & 2,30 & 2,83 & 1,18 & 3,07 & 3,82 & 1,49 & 1,0 & 3,16 & 8,14 & 2,91 & 8,17 & 1,23 & 7,47 & 22,70 \\
\hline $\mathrm{Li}$ & 12,67 & 13,50 & 29,67 & 36,00 & 32,75 & 36,00 & nd & nd & nd & nd & nd & nd & nd & nd & nd & nd \\
\hline Sn & 6,7 & 4,00 & 5,83 & 2,6 & 7,1 & 303,5 & 3,50 & 9,92 & 2,2 & 19,90 & 63,05 & 10,5 & 3,00 & 5,43 & 53,45 & 11,50 \\
\hline $\mathrm{F}$ & 897 & 745 & 1063 & 2580 & 3675 & 6567 & 2500 & 2680 & 1594 & 14500 & 7550 & 3400 & 903 & 1933 & 3288 & 4799 \\
\hline $\mathrm{Cl}$ & 692 & 178 & 446 & 361 & 101 & 52 & 955 & 795 & nd & 360 & nd & nd & 710 & 454 & 385 & nd \\
\hline W & 51,67 & 33,00 & 65,57 & 134,92 & 55,03 & 50,18 & 78,20 & 60,47 & 715 & 182,56 & 81,83 & 88,92 & 45,00 & 68,36 & 141,44 & 324,00 \\
\hline Cs & 1,07 & 0,96 & 1,45 & 1,55 & 2,27 & 0,11 & 7,34 & 5,73 & 3,6 & 8,10 & 6,75 & 4,04 & 0,85 & 2,04 & 1,93 & 2,20 \\
\hline $\mathrm{Ta}$ & 1,65 & 1,98 & 2,13 & 7,63 & 6,22 & 9,51 & 5,98 & 5,30 & 8,90 & 16,29 & 10,68 & 18,385 & 6,54 & 7,51 & 13,82 & 12,25 \\
\hline $\mathrm{Hf}$ & 7,32 & 9,81 & 5,98 & 78,60 & 60,25 & 44,33 & 8,54 & 8,38 & 12 & 6,77 & 10,48 & 12,28 & 12,62 & 15,19 & 6,94 & 7,05 \\
\hline Th & 36,33 & 43,00 & 83,00 & 32,62 & 36,33 & 38,82 & 48,01 & 45,57 & 45,1 & 51,60 & 74,40 & 58,75 & 64,75 & 69,57 & 54,68 & 61,40 \\
\hline $\mathrm{U}$ & 14,00 & 12,00 & 17,61 & 0,46 & nd & nd & 13,14 & 11,20 & 20,1 & 18,15 & 17,35 & 20,11 & 16,96 & 19,39 & 25,32 & 43,60 \\
\hline $\mathrm{La}$ & 135,33 & 272,50 & 128,37 & 100,74 & 64,25 & 32,58 & 18,49 & 18,42 & 6,14 & 58,43 & 67,72 & 60,86 & 22,64 & 28,24 & 42,60 & 47,70 \\
\hline $\mathrm{Ce}$ & 208,23 & 288,00 & 230,37 & 188,44 & 130,85 & 82,97 & 46,18 & 47,35 & 21 & 122,07 & 136,09 & 107,19 & 57,51 & 65,99 & 86,48 & 114,00 \\
\hline $\operatorname{Pr}$ & 11,07 & 36,10 & 12,61 & 18,95 & 10,73 & 11,05 & 4,87 & 5,29 & 3,42 & 11,85 & 7,49 & 10,00 & 5,54 & 6,64 & 7,57 & 12,54 \\
\hline $\mathrm{Nd}$ & 87,13 & 152,70 & 70,73 & 55,58 & 42,18 & 31,92 & 25,39 & 28,45 & 21,8 & 53,85 & 51,07 & 39,67 & 26,39 & 31,42 & 33,50 & 57,50 \\
\hline $\mathrm{Sm}$ & 18,50 & 28,25 & 12,80 & 10,88 & 10,58 & 12,03 & 7,98 & 9,49 & 9,34 & 13,56 & 11,79 & 7,90 & 7,07 & 8,43 & 8,51 & 14,95 \\
\hline $\mathrm{Eu}$ & 1,47 & 2,90 & 0,73 & 0,62 & 0,4 & 0,23 & 0,07 & 0,09 & 0,05 & 0,14 & 0,09 & 0,06 & 0,02 & 0,02 & 0,07 & 0,11 \\
\hline Dy & 16,50 & 22,45 & 8,23 & 8,82 & 12,08 & 19,40 & 14,25 & 16,78 & 25,3 & 20,67 & 20,06 & 10,79 & 9,88 & 12,29 & 14,86 & 23,80 \\
\hline Но & 1,40 & 4,93 & 1,02 & 2,21 & 2,78 & 5,14 & 3,13 & 3,64 & 6,33 & 4,51 & 4,53 & 2,48 & 2,07 & 2,60 & 3,34 & 5,29 \\
\hline $\mathrm{Er}$ & 10,00 & 20,00 & 4,63 & 5,64 & 8,23 & 13,53 & 10,51 & 12,04 & 20,5 & 15,68 & 15,89 & 9,71 & 6,70 & 8,53 & 12,14 & 17,55 \\
\hline $\mathrm{Tm}$ & 0,59 & 2,09 & 0,43 & 11,11 & 1,45 & 2,68 & 1,63 & 1,84 & 3,02 & 2,63 & 2,62 & 1,78 & 1,01 & 1,32 & 2,11 & 3,03 \\
\hline $\mathrm{Yb}$ & 11,07 & 12,00 & 4,97 & 6,74 & 10,28 & 16,67 & 11,51 & 12,77 & 19,5 & 19,66 & 19,00 & 14,22 & 6,87 & 9,16 & 16,23 & 23,00 \\
\hline $\mathrm{Lu}$ & 1,40 & 1,55 & 0,63 & 0,88 & 1,30 & 2,05 & 1,78 & 1,91 & 2,84 & 3,01 & 2,83 & 2,20 & 1,02 & 1,36 & 2,62 & 3,54 \\
\hline $\mathrm{FeO} /(\mathrm{FeO}+\mathrm{MgO})$ & 0,68 & 0,90 & 0,89 & 0,91 & 0,95 & 0,98 & ndt & ndt & ndt & ndt & ndt & ndt & ndt & ndt & ndt & ndt \\
\hline $\mathrm{Rb} / \mathrm{Sr}$ & 1,67 & 5,83 & 7,00 & 8,90 & 17,87 & 47,52 & 60,09 & 6,16 & 7,45 & 39,77 & 43,64 & 45,82 & 23,41 & 45,80 & 49,93 & 11,67 \\
\hline $\mathrm{Zr} / \mathrm{Rb}$ & 1,31 & 0,97 & 0,71 & 0,54 & 0,29 & 0,22 & 0,25 & 0,28 & 0,44 & 0,14 & 0,21 & 0,17 & 1,01 & 0,55 & 0,18 & 0,10 \\
\hline $\mathrm{Rb} / \mathrm{Ba}$ & 0,21 & 0,39 & 0,66 & 1,24 & 3,43 & 18,68 & 31,43 & 2,47 & 1,38 & 2,69 & 28,56 & 27,21 & 7,86 & 73,27 & 26,46 & 18,85 \\
\hline $\mathrm{K} / \mathrm{Rb}$ & 137 & 140 & 143 & 128 & 89 & 72 & 75 & 81 & 128 & 40 & 47 & 60 & 94 & 71 & 57 & 56 \\
\hline $\mathrm{Th} / \mathrm{U}$ & 2,59 & 3,58 & 4,71 & 70,91 & nd & nd & 3,65 & 4,07 & 2,26 & 2,84 & 4,288 & 2,92 & 3,82 & 3,59 & 2,16 & 1,41 \\
\hline $\mathrm{Th} / \mathrm{Ta}$ & 22,02 & 21,72 & 38,97 & 4,28 & 5,84 & 4,08 & 8,03 & 8,60 & 5,07 & 3,17 & 6,97 & 3,20 & 9,90 & 9,26 & 3,96 & 5,01 \\
\hline $\mathrm{Na}_{2} \mathrm{O}+\mathrm{K}_{2} \mathrm{O}$ & 8,05 & 8,12 & 8,47 & 8,02 & 8,26 & 7,99 & 8,23 & 8,05 & 8,91 & 7,28 & 7,12 & 8,41 & 8,00 & 8,37 & 7,58 & 7,21 \\
\hline $\mathrm{K}_{2} \mathrm{O} / \mathrm{Na}_{2} \mathrm{O}$ & 1,05 & 3,04 & 1,54 & 1,45 & 1,36 & 1,44 & 1,29 & 1,13 & 1,74 & 1,24 & 1,98 & 3,14 & 1,01 & 1,02 & 1,67 & 1,91 \\
\hline $\mathrm{CaO} / \mathrm{Na}_{2} \mathrm{O}+\mathrm{K}_{2} \mathrm{O}$ & 0,21 & 0,06 & 0,06 & 0,09 & 0,09 & 0,13 & 0,06 & 0,09 & 0,06 & 0,08 & 0,08 & 0,05 & 0,02 & 0,03 & 0,07 & 0,10 \\
\hline $\mathrm{F} / \mathrm{Cl}$ & 1 & 4 & 2 & 7 & 36 & 125 & 2 & 3 & nd & 40 & nd & nd & 1 & 4 & 8 & 479900 \\
\hline $\mathrm{Eu} / \mathrm{Eu}^{*}$ & 0,26 & 0,33 & 0,20 & 0,19 & 0,12 & 0,06 & 0,025 & 0,027 & 0,014 & 0,032 & 0,022 & 0,025 & 0,010 & 0,006 & 0,023 & 0,024 \\
\hline$(\mathrm{La} / \mathrm{Lu})_{\mathrm{N}}$ & 9,96 & 18,12 & 21,00 & 25,96 & 5,09 & 1,64 & 1,07 & 0,99 & 0,22 & 2,00 & 2,47 & 2,85 & 2,29 & 2,11 & 1,68 & 1,39 \\
\hline$(\mathrm{La} / \mathrm{Sm})_{\mathrm{N}}$ & 4,51 & 5,95 & 6,19 & 5,71 & 3,75 & 1,67 & 1,43 & 1,20 & 0,41 & 2,26 & 3,54 & 4,75 & 1,98 & 2,03 & 3,09 & 1,97 \\
\hline$(\mathrm{Gd} / \mathrm{Lu})_{\mathrm{N}}$ & 1,39 & 2,02 & 1,87 & 1,19 & 0,90 & 0,74 & 0,66 & 0,73 & 0,52 & 0,57 & 0,56 & 0,38 & 0,89 & 0,79 & 0,44 & 0,45 \\
\hline$\sum$ ETRL & 460,26 & 777,55 & 454,88 & 374,59 & 258,59 & 170,55 & 102,91 & 109,00 & 61,70 & 259,76 & 274,16 & 225,62 & 119,15 & 140,72 & 178,66 & 246,69 \\
\hline$\Sigma_{\text {ETRP }}$ & 57,94 & 92,48 & 30,42 & 45,51 & 47,45 & 69,80 & 54,35 & 62,75 & 93,28 & 65,01 & 80,44 & 49,34 & 36,34 & 45,82 & 63,02 & 92,84 \\
\hline$\sum$ ETR & 519,67 & 872,93 & 486,03 & 420,72 & 306,44 & 245,58 & 157,33 & 171,84 & 155,03 & 324,91 & 354,69 & 275,07 & 155,51 & 186,56 & 241,77 & 339,64 \\
\hline
\end{tabular}

BASMG=biotita-anfibólio-sieno a monzogranito, $\mathrm{BSGCl}=$ biotita-sienogranito com clorita, $\mathrm{BMG}=$ biotita-monzogranito, $\mathrm{BSG}=$ biotita-sienogranito, BSGA=biotita-sienogranito alterado, BSGIA=biotita-sienogranito intensamento alterado; BSGEm=biotita-sienogranito equigranular médio, SGH=sienogranito heterogranular, $\mathrm{MSG}=$ microssienegranito; $\mathrm{SMGP}=$ sieno a monzogranito porfirítico, $\mathrm{SGMv}=$ sienogranito com muscovita, $\mathrm{AP}=$ aplito; $\mathrm{AFG}=$ álcali-feldspatogranito, $\mathrm{BAFG}=$ biotita-álcali-feldspato-granito; $\mathrm{BSGCl}=$ biotita-sienogranito com clorita, $\mathrm{BMG}=$ biotita-monzogranito; nd=não detectado; ndt=não determinado 


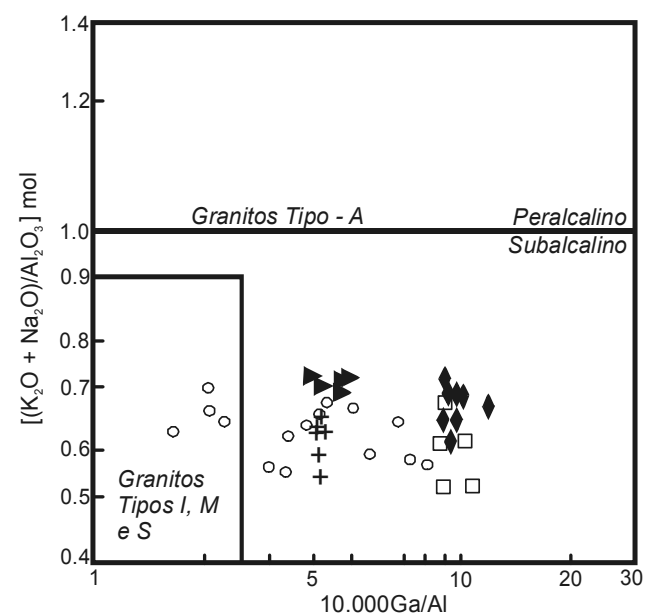

Figura 3-Diagrama $10.000 \mathrm{Ga} / \mathrm{Al}$ vs. $\left[\left(\mathrm{K}_{2} \mathrm{O}+\mathrm{Na}_{2} \mathrm{O}\right) / \mathrm{Al}_{2} \mathrm{O}_{3}\right] \mathrm{Mol}$ (Whalen et al. 1987) mostrando a distribuição composicional dos granitos da Suite Velho Guilherme. Símbolos como Fig. 2.

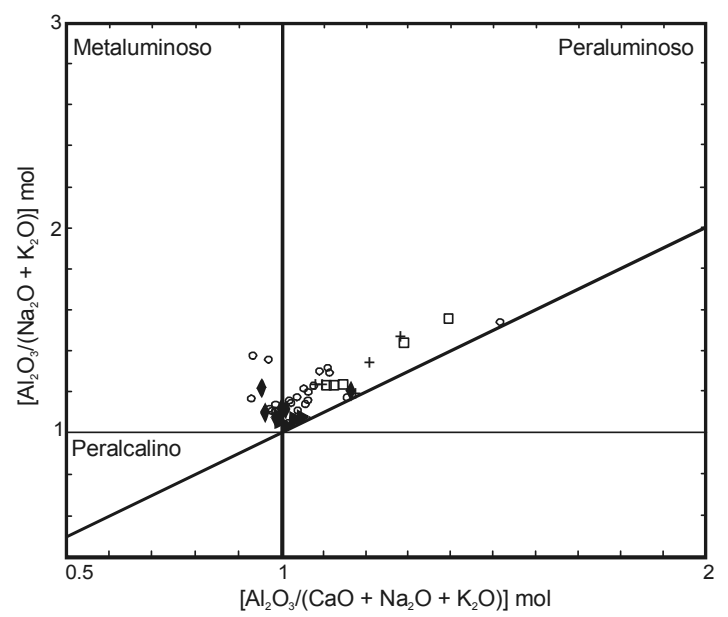

Figura 4-Diagrama A/CNK vs. A/NK (Shand 1922, Maniar \& Piccoli 1989), mostrando o caráter metaluminoso a peraluminoso dos granitos da Suite Intrusiva Velho Guilherme.

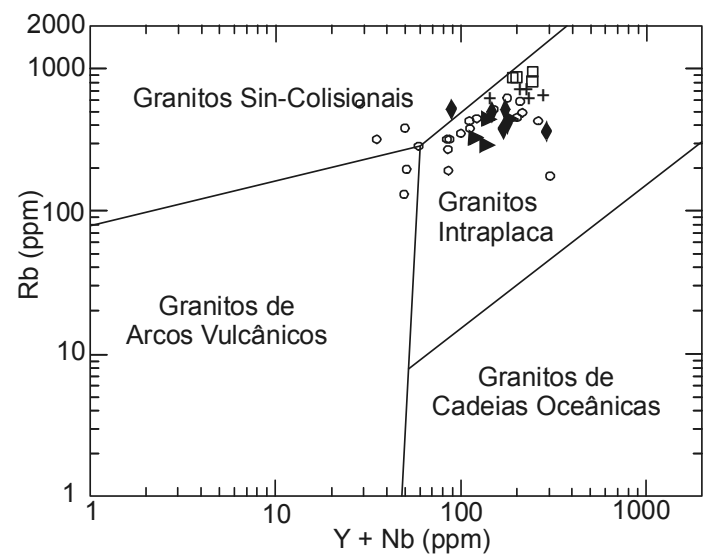

Figura 5 - Diagrama $R b-(Y+N b)$ (Pearce et al. 1984), mostrando a distribuição dos granitos da Suite Intrusiva Velho Guilherme.

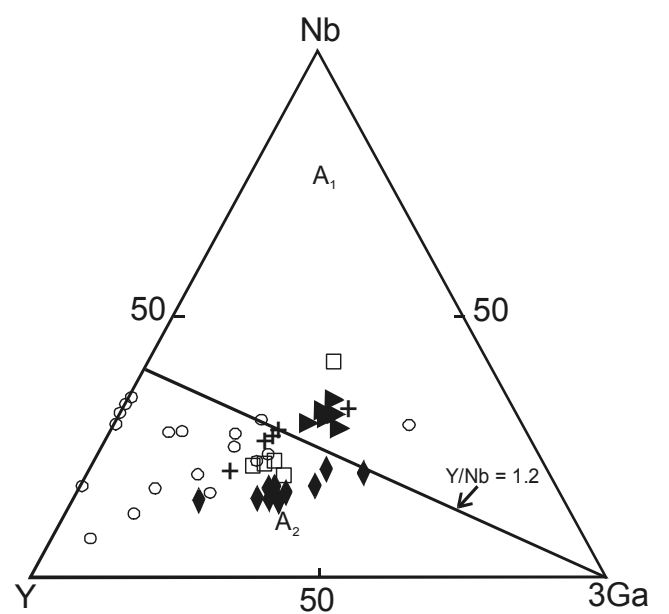

Figura 6 - Diagrama $\mathrm{Nb}-\mathrm{Y}-3 \mathrm{Ga}$ (Eby 1992), mostrando a distribuição composicional dos granitos da Suite Intrusiva Velho Guilherme.

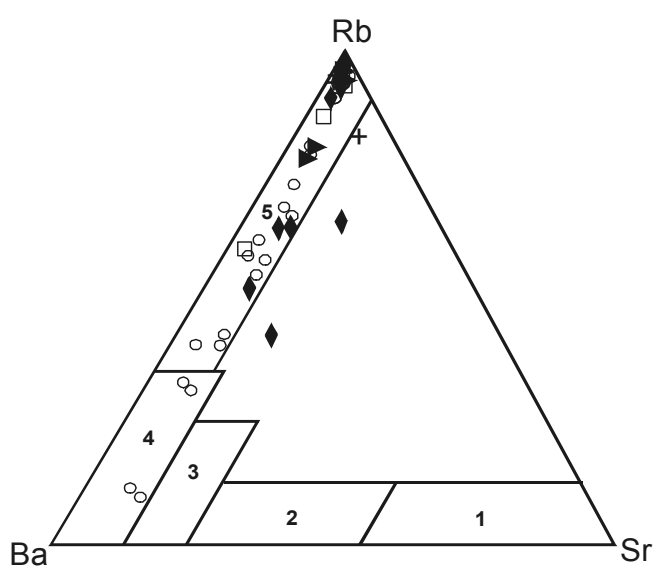

Figura 7 - Diagrama Rb-Ba-Sr (El-Bouseily \& El-Sokkary 1975), mostrando a distribuição composicional dos granitos da Suite Intrusiva Velho Guilherme. Os campos correspondem a (1) diorito, (2) granodiorito e quartzo-diorito, (3) granitos anômalos, (4) granitos normais e (5) granitos extremamente diferenciados.

o às soluções residuais onde foi oxidado, passando para a forma de $\mathrm{Sn}^{4+}$ e precipitando como cassiterita (Teixeira \& Bettencourt 2000). As fácies biotita-anfibólio-sieno a monzogranito e biotitasienogranito com clorita do maciço Antônio Vicente possuem teores de sílica abaixo da média geral da suíte (Tabela 1).

As elevadas concentrações de elementos litófilos de grande raio iônico, tais como Rb, Ke ETRL e elementos de alto potencial iônico $(\mathrm{Zr}, \mathrm{Nb}, \mathrm{e} \mathrm{Y})$, observadas nos granitos estudados, indicam que pelo menos parte das rochas fonte dos mesmos era francamente crustal.

As razões Th/Ta (Fig. 10) dos granitos dos maciços Velho Guilherme $(5,06$ a 10,46) e Benedita $(6,77$ a 15,40) sinalizam para uma fonte dominantemente de crosta continental superior. A razão $\mathrm{Th} / \mathrm{Ta}(3,52$ a 5,33) dos granitos do maciço Ubim/Sul, sugere uma fonte magmática localizada em um segmento crustal um pouco mais profundo. Já os protólitos dos granitos do maciço Mocambo $(\mathrm{Th} / \mathrm{Ta}$ de 3,03 a 8,26) correspondem possivelmente a uma mistura 

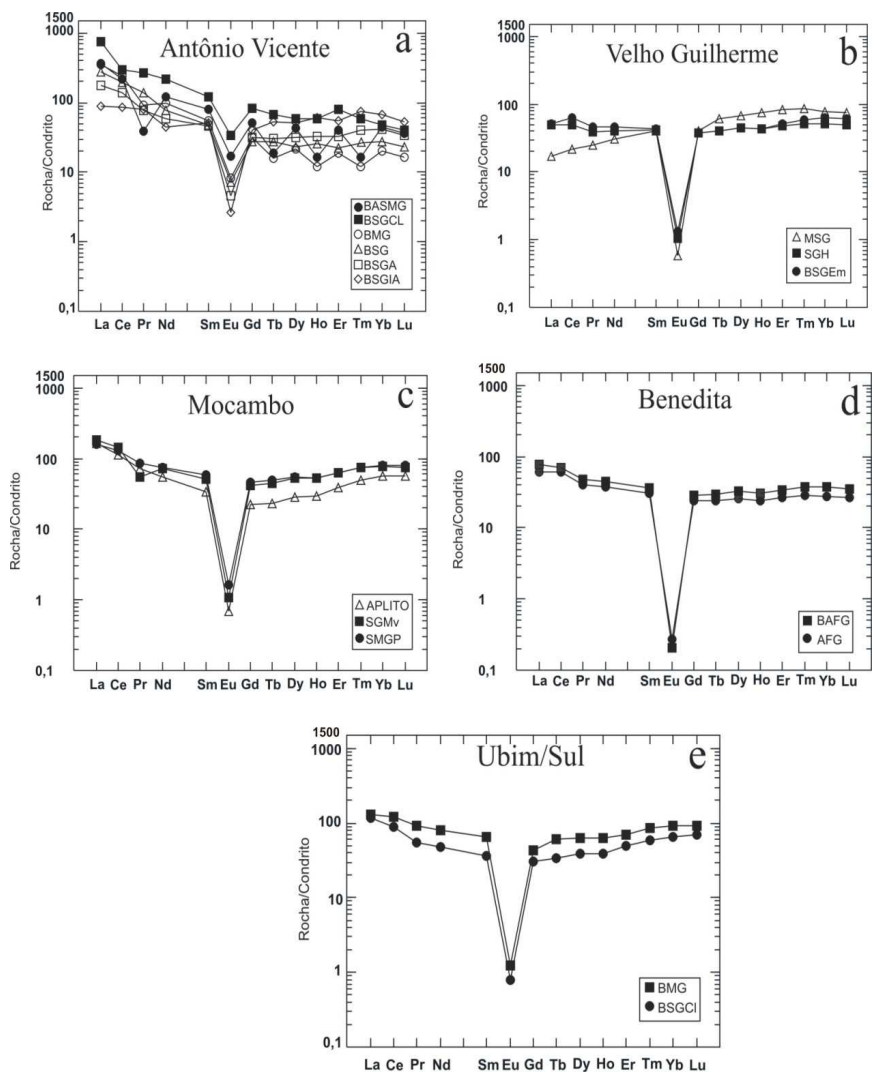

Figura 8 - Padrão de distribuição dos elementos terras raras dos granitos da Suite Intrusiva Velho Guilherme.Normalizado com base em condrito (Sun 1982).Legenda: vide Tabela 1.

de materiais de crosta continental profunda e superior. $\mathrm{O}$ amplo espalhamento composicional observado na maioria das amostras do maciço Antônio Vicente (5,0 a 100) sugere uma mistura de material da crosta continental superior com uma possível contribuição de natureza sedimentar. Quatro amostras fogem do padrão assinalado, fornecendo razões mais baixas. Uma hipótese para explicar os altos valores das razões Th/Ta encontrados em granitos do maciço Antônio Vicente seria a de que os mesmos fossem decorrentes dos processos hidrotermais pós-magmáticos que afetaram o maciço em diferentes graus. Entretanto, esta hipótese é enfraquecida, quando se observa que os granitos de outros maciços, especialmente do maciço Mocambo, também afetados por tais processos e em intensidades semelhantes, não mostram razões tão elevadas. Além disso, Th e Ta são elementos pouco móveis e deveriam ser menos afetados pelos processos hidrotermais.

As evidências geoquímicas de origem crustal para os granitos da Suíte Intrusiva Velho Guilherme aqui apresentadas, são reforçadas pelos dados isotópicos de $\mathrm{Nd}$ que revelam valores de $\varepsilon \mathrm{Nd}$ fortemente negativos $(-7,9 \mathrm{a}-12,1)$ e idades $\mathrm{T}_{\mathrm{DM}}$ arqueanas $(3,0 \mathrm{a}$ $3,2 \mathrm{Ga}$ ) para as rochas dessa suíte, interpretados como indicativos de derivação de seus magmas a partir de fontes crustais arqueanas (Teixeira et al. 2002a). Um modelo análogo foi proposto para as demais suítes anorogênicas da Província Mineral de Carajás (Dall'Agnol et al. 1999b, Rämö et al. 2002, Dall'Agnol et al. 2005)

Embora os granitos da suíte sejam diferenciados extremamente silicosos e foram afetados por processos capazes de gerar concentrações econômicas de estanho e elementos associados (depósitos dos maciços Antônio Vicente e Mocambo, por exemplo)
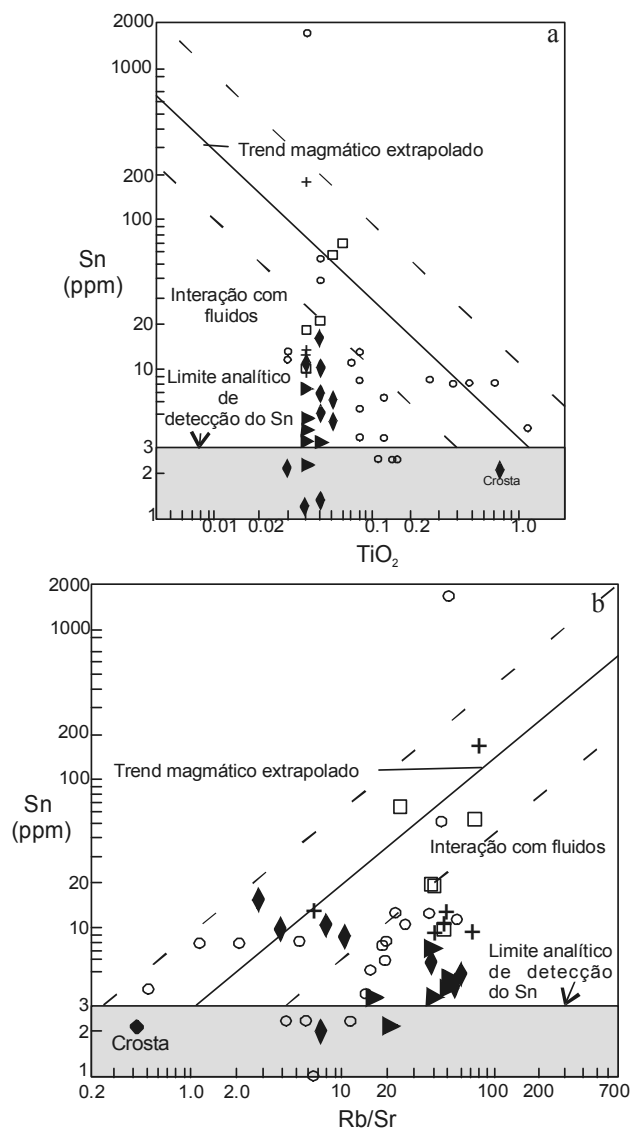

Figura 9 - Diagramas $\mathrm{Sn}$ vs. $\mathrm{TiO}_{2}$ (a) e Sn vs. Rb/Sr (b) (Lehmamm \& Mahawat 1989) mostrando a distribuição dos granitos da Suite Intrusiva Velho Guilherme. O campo da composição crustal média conforme Taylor \& McLennan (1985).

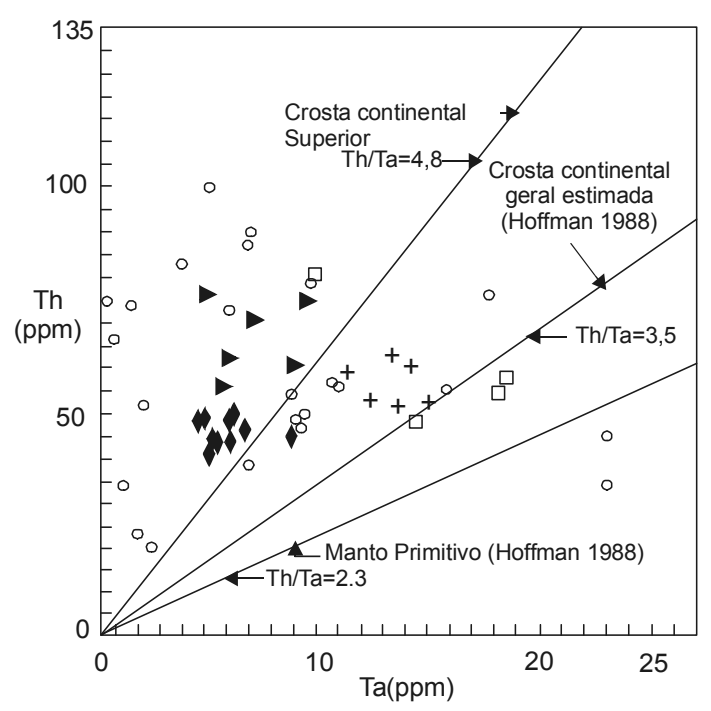

Figura 10 - Diagrama Th vs. Ta mostrando a distribuição dos granitos da Suite Intrusiva Velho Guilherme. Razões Th/Ta para o manto primitivo e crosta continental geral estimadas com base em Hoffman (1988) e para a crosta continental superior com base em Taylor \& McLennan (1985). 
constata-se que o estoque de estanho disponível ou a carga fluidal atuante no estágio pós-magmático, ou ambos, não propiciaram a formação de depósitos de classe mundial na província.

A possibilidade de existência de um estoque limitado de estanho é coerente com a hipótese assumida de derivação dos magmas graníticos a partir de uma crosta arqueana (Teixeira et al. 2002a, Dall'Agnol et al. 2005), de modo geral empobrecida em U, Th, Rb, ETRP, W, Sn, F, Be e Mo, e apresentando baixas razões K/Rb. A maior ou menor contribuição de crosta superior ou inferior como fonte dos magmas poderia explicar as variações geoquímicas observadas nos diferentes maciços. Por outro lado, os leucogranitos ricos em sílica dominantes nos vários corpos são extremamente diferenciados, indicando que os processos de diferenciação magmática foram muito atuantes. Estes mesmos leucogranitos mostram, em sua maioria, assinatura geoquímica indicando especialização para estanho, conforme se observa no diagrama $\mathrm{Sr}$ vs. $\mathrm{Rb} / \mathrm{Sr}$ (Fig. 11). Os líquidos evoluíram de modo geral em condições redutoras (Magalhães et al. 1994, Dall'Agnol et al. 2005) e as transformações pós-magmáticas foram geralmente intensas. Portanto, embora tenham existido as condições necessárias para a formação de depósitos expressivos de estanho, isto não se verificou na província, que apresenta depósitos modestos se comparados com as províncias de Rondônia (Bettencourt et al. 1995, 1999) e Pitinga (Horbe et al. 1991, Costi et al. 2000). A explicação parcial para isto reside muito provavelmente na existência de estoques mais reduzidos de estanho nas rochas fontes dos magmas graníticos, o que teria impossibilitado a formação de grandes concentrações deste metal. Além disso, é possível que o volume de fluídos atuantes durantes as alterações hidrotermais pósmagmáticas não tenha sido suficiente para proporcionar a formação de depósitos importantes, exceto localmente.

$\mathrm{O}$ conjunto de dados apresentados, somados às informações sobre isótopos de $\mathrm{Nd}$ disponíveis na literatura, sugere que os granitos da Suíte Intrusiva Velho Guilherme evoluíram a partir da fusão de diferentes segmentos crustais arqueanos, os quais não eram excepcionalmente ricos em estanho, embora tenham sido capazes de concentrar elementos produtores de calor (U, Th, Rb e K; cf. Dall'Agnol et al. 1993). A mistura em diferentes proporções de fonte de crosta inferior, relativamente empobrecida em Sn, elementos litófilos e elementos produtores de calor, com fonte de crosta continental superior, relativamente enriquecida nestes elementos, foi provavelmente o fator que determinou o grau de especialização e a capacidade de concentração de estanho dos granitos da suíte.

Outro aspecto a considerar é a importância da concentração metálica multi-cíclica, processo esse dependente de orogenias superpostas ou de magmatimo anorogênico, como condição necessária para a geração de depósitos de estanho. Os granitos dos maciços paleoproterozóicos do Cráton Amazônico, especialmente aqueles ocorrentes na área de abrangência da Província Amazônia Central (Tassinari \& Macambira 1999), são em geral estéreis (Suíte Jamon, Dall'Agnol et al. 2005), fracamente (Suíte Serra dos Carajás, Dall'Agnol et al. 2005) ou moderadamente (Suíte Velho Guilherme, Teixeira 1999) mineralizados para estanho. São exceção a isso, os granitos mineralizados da região de Pitinga (Amazonas), que hospedam importantes mineralizações de estanho e de outros metais associados (Horbe et al. 1991, Costi et al. 2000, Borges 2002). Por outro lado, os granitos jovens de Rondônia (Caritianas, Santa Bárbara, Polangueta, etc) são fortemente mineralizados em metais raros (Bettencourt et al. 1997).

A maior freqüência de concentrações anômalas de metais nos

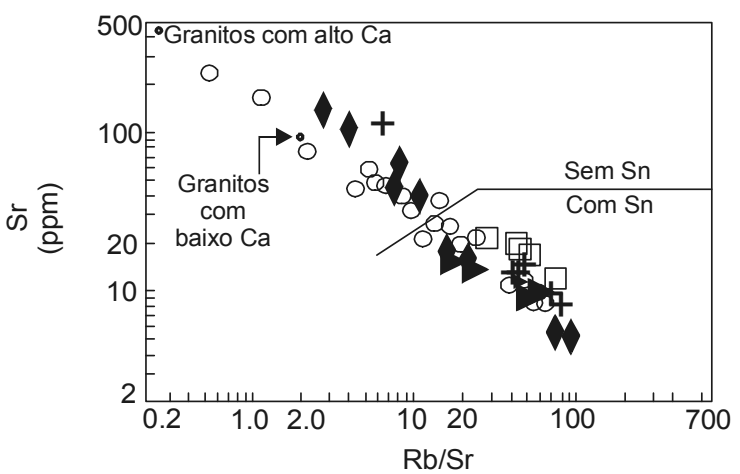

Figura 11 - Diagrama Sr vs. Rb/Sr (Lehmann \& Mahawat 1989) mostrando a distribuição composicional dos granitos da Suite Intrusiva Velho Guilherme. Os círculos menores indicam as composições médias dos granitos com alto cálcio e baixo cálcio (conforme Turekian \& Wedepohl 1961).

granitos jovens de Rondônia, quando comparados aos granitos paleoproterozóicos da Província Estanífera do Sul do Pará, ocorrentes na região de São Félix do Xingu, deve-se, pelo menos em parte, à ocorrência de processos de retrabalhamento crustal superimpostos acompanhados de sucessivos eventos magmáticos na Província Estanífera de Rondônia, os quais propiciaram excepcional enriquecimento em estanho e metais associados naquele segmento crustal do cráton.

A ausência de atividades orogênicas superpostas e de eventos magmáticos mais jovens do que $1,8 \mathrm{Ga}$ na porção leste-nordeste do Cráton Amazônico foi, talvez, o fator determinante para a ausência de depósitos de classe mundial relacionados a granitos nesta porção do cráton. Presume-se, portanto, que a crosta arqueana mais antiga era, por natureza, relativamente empobrecida em estanho e, apesar da atuação de processos de fracionamento magmático, aliados à intensa interação fluidos/rochas, não foi possível a formação de grandes depósitos na região.

CONCLUSÕES Os dados litogeoquímicos mostraram que as rochas graníticas da Suíte Intrusiva Velho Guilherme possuem natureza subalcalina, caráter metaluminoso a peraluminoso, e afinidade geoquímica com granitos intraplaca e com os granitos tipoA, do subgrupo $\mathrm{A}_{2}$.

A cristalização fracionada foi o principal processo petrogenético que governou a evolução dos granitos da suíte. Os granitos mais evoluídos $\left(\mathrm{SiO}_{2}>75 \%\right)$, hospedeiros de mineralizações de $\mathrm{Sn}$, são produtos de fracionamento magmático e da interação com fluidos aquosos pós-magmáticos ricos em voláteis $(\mathrm{F})$. Tais fluidos foram responsáveis pela extração de $\mathrm{Sn}^{2+}$, a partir das fases minerais primárias, especialmente, da biotita, incorporando-o às soluções residuais onde foi oxidado, passando para a forma ${\mathrm{de} \mathrm{Sn}^{4+}}^{4}$ precipitando como cassiterita.

Os altos teores de elementos litófilos de grande raio iônico, tais como Rb, Ke ETRL, e elementos de alto potencial iônico ( $\mathrm{Zr}$, $\mathrm{Nb}$ e $\mathrm{Y}$ ), observados nos granitos da suíte, somados aos dados isotópicos de $\mathrm{Nd}$ disponíveis na literatura, indicam que as rochas fonte dos seus magmas eram francamente crustais.

As razões Th/Ta sinalizam para uma fonte dominantemente de crosta continental superior para os granitos dos maciços Velho Guilherme e Benedita, uma fonte magmática crustal um pouco mais profunda para os granitos do maciço Ubim/Sul, uma mistura de 
materiais de crosta profunda e superior para os protólitos dos granitos do maciço Mocambo e uma mistura de material da crosta continental superior com possível contribuição sedimentar para os granitos do maciço Antônio Vicente.

Embora os granitos da suíte sejam extremamente diferenciados e foram afetados por processos capazes de gerar concentrações econômicas de estanho, o estoque de estanho ou a carga fluidal atuante no estágio pós-magmático ou ambos não propiciaram a formação de depósitos de classe mundial na província que apresenta depósitos modestos se comparados com as províncias de Rondônia e Pitinga. Isso se deve provavelmente à existência de estoques mais reduzidos de estanho nas rochas fontes arqueanas dos magmas graníticos e, talvez, a um volume não muito elevado de fluídos, o que teria impossibilitado a formação de grandes concentrações deste metal. A mistura em diferentes proporções de fonte de crosta inferior, relativamente empobrecida em Sn, elementos litófilos e elementos produtores de calor, com fonte de crosta continental superior, relativamente enriquecida nestes elementos, foi provavelmente o fator que determinou o grau de especialização e a capacidade de concentração de estanho dos granitos da suíte.
Agradecimentos À FAPESP, Fundação de Apoio a Pesquisa do Estado de São Paulo, pelo apoio financeiro para a realização das análises (Projeto 96/3942-0); ao CNPq pelo apoio financeiro (Processos RD 550739/01-7 e 476075/03-3); R. Dall'Agnol agradece ao Serviço de Análises e à direção do Centre des Recherches Pétrographiques et Géochimiques (CRPG, Vandoeuvre - Lès Nancy, França) por parte das análises químicas; à Mineração Taboca e aos geólogos Carlos Augusto Sena Sá, Tadeu Veiga, Germano José Reabe, Hilton Coelho e Evandro Cintra e aos técnicos Quegenaldo e Seabra pela hospedagem e apoio durante grande parte dos trabalho de campo no maciço Antônio Vicente; à CPRM e aos geólogos Edésio José Buenano Macambira e Xafi da Silva Jorge João, pelo apoio nos trabalhos de campo e informações sobre a geologia da Folha SB-22-Y-B (Folha São Felix do Xingu); à Mineração São Francisco de Assis (Projeto Mocambo), nas pessoas do administrador Adalberto Maia e do técnico Manuel Correa, pelo apoio durante trabalhos de campo no maciço Mocambo. Este trabalho é uma contribuição aos projetos IGCP510 (IUGS-UNESCO) e PRONEX (103-98/MCT/CNPq-Proc. $66.2103 / 98-0)$.

\section{Referências}

Abreu F.A.M. \& Ramos C.R. 1974. Estanho do Sul do Pará. In: SBG, Congr. Bras. Geol., 28, Porto Alegre, Anais, 5:11-23.

Almeida F.F.M., Hasui Y., Brito Neves B.B. de, Fuck R.A. 1981. Brazilian Structural Provinces: an introduction. Earth Sci. Rev., 17:1-29.

Araújo O.J.B., Maia R.G.N., Jorge João X.S., Costa J.B.S. 1988. A megaestruturação da Serra dos Carajás. In: SBG, Congr. Latinoamer. Geol., 7, Belém, Anais, 1:324-338.

Bettencourt J.S., Dall'Agnol R. 1987. The Rondonian tin-bearing anorogenic granites and associated mineralization. In: Intern. Symp. Granites and Assoc. Mineraliz., Salvador, Excursion Guides, pp.49-87.

Bettencourt J.S., Tosdal R.M., Leite Jr. W.B., Payolla B.L. 1995. Overview of the rapakivi granites of the Rondônia Tin Province (RTP). In: J.S. Bettencourt \& R. Dall'Agnol (Eds.). 1995. Excursion Guide: The rapakivi granites of the Rondônia Tin Province and associated mineralization. IGCP PROJECT 315. Belém, Pará, Brasil. 48p.

Bettencourt J.S., Leite W.B., Payolla B.L., Scandolara J.E., Muzzolon R., Vian J.A.J. 1997. The rapakivi granites of the Rondônia Tin Province, northern Brazil. In: Intern. Symp. Granites and Associated Mineralizations, Salvador, Excursion Guide, pp.3-31.

Bettencourt J.S., Tosdal R.M., Leite Jr. W.B, Payolla B.L. 1999. Mesoproterozoic rapakivi granites of the Rondônia Tin Province, southwestern border of the Amazonian craton, Brazil - I. Reconnaissance $\mathrm{U}-\mathrm{Pb}$ geochronology and regional implications. Prec. Res., 95:41-67.

Borges R.M.K. 2002. Greisens e epissienitos potássicos associados ao Granito Água Boa, Pitinga (AM): um estudo dos processos hidrotermais geradores de mineralizações estaniferas. C. de Geociências, Universidade Federal do Pará, Belém, Tese de Doutorado, 383p

Collins W.J., Beams S.D., White A.J., Chapell B.W. 1982. Nature and origin of A-type Granites with particular reference to Southeastern Australia. Contr. Mineral. Petrol., 80:189-200.

Costi H.T., Dall'Agnol R., Moura C.A.V. 2000. Geology and Pb-Pb Geochronology of Paleoproterozoic Volcanic and Granitic Rocks of
Pitinga Province, Amazonian Craton, Northern Brazil. Intern. Geol. Review, 42: 832-849.

CPRM/DNPM. 1997. Programa levantamentos geológicos básicos do Brasil. São Felix do Xingu. Folha SB-22-Y-B. Estado do Pará. Brasília. $344 \mathrm{p}$.

Dall'Agnol R. 1980. Etudes sur des granites du type "Rondonian" en Amazonie Orientale et leurs transformations tardi-magmatiques. Laboratoire de Geologie, Université, Paul Sabatier, Tolouse, These Troisieme Cycle, 348p.

Dall'Agnol R., Vieira E.A.P., Sá C.A.S., Medeiros H., Gastal M.C.P., Teixeira N.P. 1986. Estado atual do conhecimento sobre as rochas granitóides da porção sul da Amazônia Oriental. Rev. Bras. Geoc., 16:11-23.

Dall'Agnol R., Teixeira N.P., Magalhães M.S. 1993. Diagnostic features of the Tin-specialized anorogenic granites of the Eastern Amazonian Region. Anais Acad. Bras. Ciências, 65 (Supl 1):33-50.

Dall'Agnol R., Teixeira N.P., Magalhães M.S. 1994. The anorogenic leucogranites of the eastern Amazonian region: an example of tinmineralized granites of the rapakivi series. In: Anortosites, Rapakivi Granites and Related Rocks, International Geological Correlation Programme, Joint meeting IGCP Nos 290 and 315, Program and Abstracts. McGill University, Montreal, p.2.

Dall'Agnol R., Costi H.T., Leite A.A. da, Magalhães M.S. de, Teixeira N.P. 1999a. Rapakivi granites from Brazil and adjacent areas. Prec. Res., 95:9-39.

Dall'Agnol R., Rämö O.T., Magalhães M.S., Macambira M.J.B. 1999b. Petrology of the anorogenic, oxidised Jamon and Musa granites, Amazonian craton: implications for genesis of Proterozoic A-type granites. Lithos 46:431-462.

Dall'Agnol R., Teixeira N.P., Rämö O.T., Moura C.A.V., Macambira M.J.B., Bettencourt J.S. 2005. Petrogenesis of the Paleoproterozoic, Rapakivi, A-Type Granites of the Carajás Mining Province. Lithos, 80:101-129.

Daoud W.K. 1988. Granitos estaniferos de Pitinga, Amazonas: contexto geológico e depósitos minerais associados. Dep. Geociências, UnB, 
Brasília, Dissertação de Mestrado, 194p.

Eby G.N. 1992. Chemical subdivision of the A-tipe granitoids: petrogeneses and tectonic implications. Geology, 20:641-644.

El-Bouseily A.M. \& El-Sokkary A.A. 1975. The relation between Rb, $\mathrm{Ba}$ and Sr in granitic rocks. Chem. Geol., 16:207-219.

Fernandes C.M.D. 2003. Quimica Mineral da Mica Branca de Rochas Graniticas e Greisens da Suite Inrusiva Velho Guilherme, Província Estanifera do Sul do Pará. C. Geociências, Universidade Federal do Pará, Tabalho de Conclusão de Curso, Belém, 33p.

Gastal M.C.P. 1987. Maciço Granítico Musa: Mapeamento, Petrologia e Petroquímica, Rio Maria, SE do Pará. C. Geociências, Universidade Federal do Pará, Belém, Tese de Mestrado, 327p.

Gonçalez M.G.B., Vieira E.A.T., Dall'Agnol R., Macambira M.J.B., Angelim E.P.V., Senta N.D. 1988. Geologia do Maciço Anorogênico Cigano. Vale do Rio Parauapebas-PA. In: SBG, Congr. Bras. Geol, 35, Belém, Anais, 3:1132-1146.

Hofmann A.W. 1988. Chemical differentiation of the Earth: the relationship between mantle, continental crust, and oceanic crust. Earth Plan. Sci. Lett., 90:297-314.

Horbe M.A., Horbe A.C., Costi H.T., Teixeira J.T.1991. Geochemical characteristics of cryolite-tin-bearing granites from Pitinga Mine, northwestern Brazil - a review. J. Geoch.. Expl., 40:227-249.

Lafon J.M., Pereira E.D., Macambira E.M.B., Vale A.G., Barradas J.A.S. 1991. Geocronologia Rb-Sr da região de São Felix do Xingu. Resultados preliminares. In: SBG, Symp. Geol. Amaz., 3, Belém, Anais, 1:21-35.

Lafon J.M., Rodrigues E., Macambira E.M.B., Pereira E.D. 1995. Magmatisme anarogénique du Protérozoique Inférieur dans la région de São Felix do Xingu-Tucumã (Amazonie Orientale, Brésil). Nouvelles données geochronologiques. C. R. Acad. Sci. Paris, 320:937-944.

Lamarão C.N., Dall'Agnol R., Lafon J.M., Lima E.F. 2002. Dois eventos vulcânicos paleoproterozóicos na Província Aurífera do Tapajós: novos dados isotópicos $\mathrm{Sm}-\mathrm{Nd}$ e implicações para o Supergrupo Uatumã. In: SBG, Simp. Vulcanismo e Ambientes associados, Belém, Boletim de Resumos e Roteiro da Excursão, p.27.

Lehmann B. \& Mahawat C. 1989. Metallogeny of tin in central Thailand: A genetic concept. Geology, 17:426-429.

Le Maitre R. W. 1976. The chemical variability of some common igneous rocks. Journ. Petrol., 17(4):589-637.

Loiselle M.C. \& Wones D.R., 1979. Characteristics and origin of anarogenic granites. Geol. Soc. Am. Abst. Prog., 11:468.

Magalhães M.S., Dall'Agnol R., Sauck W.A., Luiz J.G. 1984. Suscetibilidade magnética: um indicador da evolução petrológica de granitóides da Amazônia. Rev. Bras. Geoc. 24:139-149

Maniar P.D. \& Piccoli P.M. 1989. Tectonic discrimination of granitoids. Geol. Soc. Amer. Bull. 101:635-643.

Medeiros H., Gastal M.C.P., Dall'Agnol R., Souza Z.S. 1987. Geology of the Rio Maria area (Estern Amazonian region-Brazil): an example of Archean granite-greenstone terrane intruded by anorogenic granites of Middle Proterozoic age. In: IUGS-Unesco, Final Meeting of 204IGCP Project, Carajás, Extended Abstract, pp.97-109.

Pearce J.A., Harris N.B.W, Tindle A.C. 1984. Trace Elements discrimination diagrams for the tectonic interpretation of granitic rocks. Jour. Petrol., 25:956-983.
Pitcher W.S. 1979. The nature, ascent and empacement of granitic magmas. Journ. Geol. Soc London, 136:627-662.

Rämö O.T, Van Schmus W., Bettencourt J.S. 2002. Preface: IGCP prpject 426-Granite Systems and Proterozoic Lithospheric Processes. Prec. Research, 119:1-7.

Shand S.J. 1922. The Problem of the Alcaline Rocks. Proc. Geol. Soc. S. Afr., 25, XIX-XXXIII.

Shaw D.M. 1968. A review of K-Rb fractionation trends by covariance analysis. Geochm. Cosmochm. Acta, 32:573-601.

Smith J.V. \& Brown W.L. 1988. Feldspar minerals. 2nd Ed. Berlin, SpringVerlag, 828p.

Streckeisen A. 1976. To each plutonic rocks its proper name. Earth Sci. Rev., 12:1-33.

Sun S.S. 1982. Chemical composition and origin of the Earth's primitive mantle. Geochm. Cosmoch. Acta., 46:179-197.

Tassinari C.C.G. \& Macambira M.J.B. 1999. Geochronological provinces of the Amazonian craton. Episodes, 22:174-182.

Taylor S.R. \& McLennan S.M. 1985. The continental crust: its composition and evolution. London, Blackwell Scientific Publications. 312p.

Teixeira N.P. \& Dall'Agnol R. 1991. Geologia e petrografia do Maciço Granítico Antônio Vicente. Região de São Félix do Xingu/PA. Bol. Mus. Par. Emílio Goeldi. Ciências da Terra, 3:45-73.

Teixeira N.P. \& Andrade W.L.G. 1992. Caracterização Petrográfica dos stocks graníticos Benedita e Ubim/Sul. Região de São Felix do Xingu/ PA. Bol. Mus. Par. Emílio Goeldi, Ciências da Terra, 4:3-33.

Teixeira N.P. 1999. Contribuição ao estudo das rochas granitóides e mineralizações associadas da Suite Intrusiva Velho Guilherme, Província Estanifera do Sul do Pará. Instituto de Geociências, USP, São Paulo, Tese de Doutoramento, 508p.

Teixeira N.P. \& Bettencourt J.S. 2000. Velho Guilherme Intrusive Suite. Pará, Brazil: petrogenetic aspects and associated mineralization. In: Intern. Geol. Congr., 31, Rio de Janeiro. Abstract. Granite Systems and Proterozoic Lithospheric Processes IGCP-426, IAGC/IMA. CDROM.

Teixeira N.P., Bettencourt J.S., Moura C.A.V., Dall'Agnol R., Macambira E.M.B. 2002a. Archen crustal sources for paleoproterozoic tingranites in the Carajás Province, SSE Pará, Brazil: $\mathrm{Pb}-\mathrm{Pb}$ geochronology and $\mathrm{Nd}$ isotope geochemistry. Prec. Res., 119(14):2257-2275.

Teixeira N.P., Bello R.M.S., Bettencourt J.S. 2002b. Inclusões fluidas do maciço Antônio Vicente, Suíte Intrusiva Velho Guilherme, Província Estanífera do Sul do Pará. Rev. Bras. Geoc., 32(1):135-146.

Turekian K.K \& Wedepohl K.H. 1961. Distribuition of the elements in some major units of the Earth's crust. GSA. Bull. 72:172-202.

Tuttle O.F. \& Bowen N.L. 1958. Origin of granite in the light of experimental studies in the system NaA1Si3O8-SiO2-H2O. GSA Memoir, 74:1-153p.

Whalen J.B., Currie K.L., Chappell B.W.1987. A-Type granite: geochemical characteristics, discrimination and petrogenesis. Contr. Mineral. Petrol., 95:407-419.

Manuscrito A-1460

Recebido em 11 de agosto de 2003

Revisão dos autores em 30 de abril de 2005 Revisão aceita em 15 de maio de 2005 